\title{
Estudio de la calidad de vida relacionada con la salud del donante de vivo renal
}

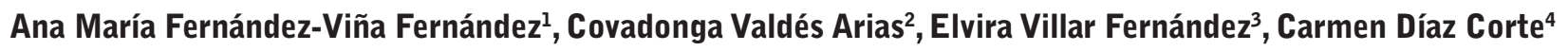 \\ ${ }^{1}$ Diplomada Universitaria Enfermería, ${ }^{2}$ Licenciada en Psicología, ${ }^{3}$ Auxiliar Administrativo, Hospital Universitario \\ Central de Asturias. Oviedo. España
}

\section{Resumen}

Los diversos estudios que evalúan la calidad de vida relacionada con la salud (CVRS) de los donantes de vivo renales encuentran que es comparable a la de la población general, o superior, independientemente del tiempo desde del trasplante.

Objetivo: Evaluar la CVRS de los donantes de vivo renales y analizar aspectos relacionados con el proceso de la donación.

Material y Métodos: Se contactó telefónicamente con los donantes de trasplantes renales de vivo realizados hasta este momento en el Hospital Universitario Central de Asturias, y a los que quisieron participar se les auto-administró el Cuestionario de salud SF-36 versión 2.

A su vez se recogieron variables sobre la donación, sociodemográficas y clínicas.

\section{Resultados}

De los 29 donantes, 25 fueron mujeres (edad $52 \pm 11$ ). Dos receptores perdieron el trasplante y un donante falleció. El $41 \%$ fueron cónyuges, el $28 \%$ madres, el $24 \%$ hermanos y el $7 \%$ cuñados de los receptores. La creatinina pre-trasplante fue $0,71 \pm 0,11 \mathrm{mg} / \mathrm{dL}$ y al alta 1,05 $\pm 0,22 \mathrm{mg} / \mathrm{dL}$. El 55\% sufrieron algún efecto adverso siendo dolores abdominales y molestias en la herida los más habituales, y aunque no se encontraron diferencias estadísticas entre laparoscopia y lumbotomía, estos últimos tuvieron un ingreso más prolongado $7 \pm 2$ vs $5 \pm 1$ días $(p=0,015)$. Las puntuaciones en

Correspondencia:

Ana María Fernández-Viña Fernández

Consulta de trasplante renal

Hospital Universitario Central de Asturias

Avda. de Roma. 33011 Oviedo

E-mail:anafvf@gmail.com el cuestionario de CVRS fueron similares a las de la población general en todas las dimensiones y el $100 \%$ volverían a donar.

\section{Conclusiones}

La CVRS de los donantes post-trasplante fue comparable a la población general. Por otro lado los donantes no se arrepienten de la decisión de donar independientemente de los efectos secundarios sufridos o los resultados del trasplante en el receptor.

PALABRAS CLAVE

- CALIDAD DE VIDA RELACIONADA CON LA SALUD

- DONANTE DE VIVO RENAL

- TRASPLANTE RENAL DE VIVO

A study of the health-related quality of life in living kidney donors

\section{Abstract}

Studies evaluating the health-related quality of life (HRQOL) in living kidney donors find it comparable to the general population or greater, regardless of the time since transplant.

Objective: To assess the HRQOL of the living kidney donors and to analyse the aspects related to the donation process.

Methods: We contacted by telephone with all living kidney donors performed at the Hospital Universitario Central de Asturias, and those who wanted to participate completed the SF-36 v.2 questionnaire.

Donation process, sociodemographic and clinical variables were collected. 


\section{Results}

Out of the 29 donors, 25 were women (age $52 \pm 11$ ). Two receivers rejected the graft and one donor died. $41 \%$ were spouses, $28 \%$ mothers, $24 \%$ brothers and $7 \%$ brother in law. Mean pre-transplant creatinine was $0.71 \pm 0.11 \mathrm{mg} / \mathrm{dL} ;$ and at discharge $1.05 \pm 0.22 \mathrm{mg} /$ dL. $55 \%$ suffered some adverse effect, with abdominal pain and discomfort as the most common. Although no statistical differences between laparoscopic and lumbotomy were found, the latter had a more prolonged hospital stay $(7 \pm 2$ vs. $5 \pm 1$ days; $p=0.015)$. Scores on the HRQL questionnaire were similar to those of the general population in all dimensions and $100 \%$ return to donate.

\section{Conclusions}

Post-transplant donors' $\mathrm{HRQL}$ was comparable to that of the general population. On the other hand donors do not regret the decision to donate regardless of the suffering side effects or results of transplantation at the receiver.

\section{KEYWORDS}

\section{- HEALTH-RELATED QUALITY OF LIFE \\ - LIVING KIDNEY DONOR \\ - LIVING DONOR TRANSPLANT}

\section{Introducción}

Para la mayor parte de los pacientes con enfermedad renal crónica avanzada (ERCA) el trasplante renal es la mejor opción ya que proporciona mejor supervivencia y mejor CVRS, y más aún cuando se produce de forma preventiva evitando que los pacientes sufran las consecuencias de la diálisis. Además, a pesar de la alta tasa de reingresos que presentan los pacientes en el primer año post-trasplante y del exhaustivo control que necesitan, que equiparan el coste de ese primer año al de la diálisis, el trasplante es una de las intervenciones más coste-efectivas, ya que, después, los costes anuales son muy inferiores. Sin embargo, el número de trasplantes anuales apenas ha aumentado en la última década, la cantidad de donantes cadáver de riñón disponibles no es suficiente para cubrir la demanda, y el número de pacientes en lista de espera se va incrementando․ Es esta situación la que hace que el trasplante de riñón de donante de vivo esté en la última década extendiéndose en nuestro país, ya que proporciona excelentes resultados para los receptores y es una alternativa principalmente para aquellos pacientes que por sus características demográficas o clí- nicas, permanecen largo tiempo en lista de espera sin que aparezca un donante apto para ellos. Y dado que la seguridad del donante es esencial para continuar con estos procedimientos surge la necesidad de investigar los resultados, y repercusiones en los donantes a largo plazo que aún no han sido bien estudiados. Entre esos resultados se encuentran las medidas de CVRS que son un indicador muy tenido en cuenta desde hace años en los resultados en salud.

Hasta la fecha, la mayor parte de los estudios llevados a cabo para valorar posibles consecuencias en la salud encuentran que no hay un decremento en la supervivencia ni una disfunción renal en donantes de riñón de vivo, si bien no hay un acuerdo claro sobre la existencia de una mayor prevalencia de hipertensión después de la donación².

En relación a la CVRS de los donantes parece ser que es similar o incluso mejor que la de la población general $^{2}$, si bien algunos autores encuentran algún deterioro en la salud física después de la cirugía hasta al menos los tres meses aunque vuelve al nivel basal al año de la donación ${ }^{3}$. En un estudio a largo plazo donde también encuentran que los donantes de riñón viven más, posiblemente por un sesgo de selección de individuos sanos, y destacan que la función renal se recupera inicialmente después de la donación y por un largo periodo de tiempo, pero a largo plazo sí se produce una disminución principalmente en los pacientes más mayores ${ }^{4}$.

En relación a los factores que afectan a los aspectos físicos de la CVRS, la obesidad, la historia previa de problemas psiquiátricos y la raza no blanca fueron los factores asociados a una disminución de la salud física ${ }^{5}$. Por su lado los aspectos mentales de la CVRS del donante parecen verse afectados por los resultados del trasplante, las expectativas previas y por la percepción que el donante hace sobre la salud del receptor ${ }^{3,4}$. La historia previa de problemas psiquiátricos también parece ser un factor de riesgo para un deterioro en la salud mental, mientras que una mayor edad en el momento de la donación y una relación en primer grado con el receptor son protectores ${ }^{5}$. Un estudio concluye que la CVRS del donante con receptor fallecido declina pero se recupera, mientras que la de los donantes con receptores que perdieron el injerto declina y ya no se recupera ${ }^{6}$.

Otro estudio, Ilevado a cabo recientemente en Francia, donde al igual que en España el trasplante renal de vivo está aún poco extendido, también encontró que los donantes tenían una excelente CVRS en los aspectos físicos, especialmente los de más edad al compa- 
rarlos con los de su misma edad y sexo. El único factor que influyó en los resultados fue la técnica quirúrgica ya que los donantes operados con cirugía laparoscópica tuvieron menos dolor post-operatorio. También encontraron que los donantes estuvieron satisfechos con la información sobre la donación a excepción de las consecuencias del dolor y molestias en la herida y que el $98 \%$ donaría de nuevo ${ }^{7}$.

Sobre las cirugías empleadas, las técnicas endoscópicas han contribuido a una mejor recuperación y a un incremento de la CVRS en los donantes. Dado que la nefrectomía laparoscópica estándar del donante puede tener sus limitaciones, se ha introducido la nefrectomía laparoscópica mano-asistida como una alternativa más segura. Los datos demuestran que en la cirugía mano-asistida la isquemia caliente es más corta, aunque hay un incremento en la pérdida de sangre, pero no se encontraron diferencias en la CVRS, tasa de complicaciones, dolor, o estancias hospitalarias $^{7,8}$.

\section{Objetivos}

1) Evaluar la CVRS de los donantes de vivo de la consulta de trasplante del Hospital Universitario Central de Asturias.

2) Analizar aspectos relacionados con el donante, el receptor y el proceso de la donación que puedan afectar a los donantes.

3) Conocer las vivencias y los posibles perjuicios ocasionados con la donación.

\section{Material y métodos}

Se estudian todos los trasplantes renales de donante vivo realizados en el Hospital Universitario Central de Asturias hasta el mes de marzo de 2014. Se contactó telefónicamente con todos los donantes para explicarles la naturaleza y objetivos del estudio y los que quisieron y pudieron participar fueron citados ese mismo mes en la consulta de trasplante renal. Los criterios de inclusión fueron: no estar ingresado en el momento del estudio, llevar como mínimo un mes post-donación, poseer capacidad física y cognitiva para responder a los cuestionarios, y otorgar consentimiento para participar. Se recogieron variables sociodemográficas: edad, sexo, parentesco con el receptor, nivel de estudios completados (leer y escribir; primarios; bachiller/FP; universitarios); situación laboral (trabaja a media jornada o a jornada completa; estudia; ama de casa; en paro; jubilado por enfermedad o por edad) y país de origen.
Para evaluar su CVRS se usó el Cuestionario de salud SF-36 versión 2 (SF-36v2) que incluye 36 ítems, agrupados en ocho dimensiones y dos puntuaciones resumen: estado de salud física (PCS) y estado de salud mental (MCS). Las puntuaciones de cada dimensión van de 0 (peor estado de salud) a 100 (mejor estado de salud). EI SF-36v2 permite estandarizar las puntuaciones sobre la base de normas poblacionales cuyas medias son $50 \pm 10^{10}$. En la entrevista el donante también contestó al Checklist para las entrevistas con donantes de riñón de vivo propuesto por Casares ${ }^{11} \mathrm{y}$ también se les preguntó si volverían a donar después de lo vivido. Se valoró asimismo el estado funcional con la escala de Karnofs$\mathrm{ky}^{12}$.

A su vez se recogieron de la historia clínica aspectos relacionados con los perjuicios que han podido tener como consecuencia de la donación: duración del ingreso hospitalario, número de días de visita al hospital y número de consultas necesarias pre y posttrasplante. Otras variables clínicas recogidas fueron la fecha del trasplante, la técnica quirúrgica utilizada, cirugía abierta o cirugía laparoscópica mano asistida, índice de masa corporal (IMC), presión arterial pretrasplante y post-trasplante, la creatinina antes de la donación, al alta, y a los 3, 6, 12 meses y la última disponible. Por último, se recogieron todos los efectos adversos acontecidos tras el acto quirúrgico en la historia del donante, así como la situación del injerto donado y del receptor.

Con el paquete estadístico SPSS 15.0 se realizó el estudio descriptivo de la muestra, y posteriormente se buscaron las relaciones de asociación con el estadístico $\mathrm{X}^{2}$ para la comparación de dos proporciones y con la $t$ de Student para la comparación de dos medias independientes. Se analizaron las correlaciones con la prueba de Pearson para variables cuantitativas continuas y Spearman para cuantitativas discretas, destacando siempre las diferencias con significación $p<0,05$.

\section{Resultados}

Hasta marzo del año 2014 se han realizado en el Hospital Universitario de Asturias 29 trasplantes renales de donante vivo. La mediana de tiempo desde el trasplante fue de 30 meses (Pc25=19-Pc75=43). De los 29 donantes, 25 fueron mujeres ( $86 \%$ ), la edad media en el momento de la donación fue de $52 \pm 11$ años y en el momento del presente estudio de $55 \pm 10$ años. El $78 \%$ tenía estudios elementales y un $24 \%$ vida laboral activa. Del total de donantes, $6(21 \%)$ eran originarios de otros países, y el $93 \%$ eran católicos. 
En relación a la tensión arterial la media de la tensión arterial sistólica (PAS) previa a la donación, recogida por MAPA fue de $118 \pm 14 \mathrm{mmHg}$ y la diastólica (PAD) $72 \pm 8 \mathrm{~mm} \mathrm{Hg}$, mientras que en el momento de la entrevista la tensión arterial sistólica recogida con tensiómetro digital fue de $131 \pm 22 \mathrm{mmHg}$ y la diastólica de $82 \pm 12 \mathrm{mmHg}$. La media del IMC fue de $28 \pm 3$ $\left(\mathrm{kg} \cdot \mathrm{m}^{2}\right)$. La media de consultas pre y post-trasplante realizadas en el hospital en relación al acto de la donación fue de $18 \pm 6$ y las visitas hospitalarias necesarias para realizarlas $15 \pm 6$. El $38 \%$ fue sometido a cirugía abierta, lumbotomía, y el $62 \%$ restante a cirugía laparoscópica mano-asistida. La duración del ingreso para la realización de la nefrectomía fue de 6 \pm 2 días como muestra la Tabla 1 .

Tabla 1. Datos del donante

\begin{tabular}{|c|c|}
\hline $\begin{array}{l}\text { Edad en el momento de la donación } \\
(M \pm D E)\end{array}$ & $52 \pm 11$ \\
\hline Sexo (\%) Mujeres & $86 \%$ \\
\hline Religión Católica & $93 \%$ \\
\hline Originarios de otros países & $21 \%$ \\
\hline Nivel de educación bajo/elemental (\%) & $78 \%$ \\
\hline Vida laboral activa (\%) & $24 \%$ \\
\hline PAS Pre-donación ( $M \pm D E)$ & $118 \pm 14 \mathrm{mmHg}$ \\
\hline PAD Pre-donación $(\mathrm{M} \pm \mathrm{DE})$ & $72 \pm 8 \mathrm{mmHg}$ \\
\hline $\begin{array}{l}\text { Consultas pre y post-trasplante } \\
\text { realizadas en el hospital }(M \pm D E)\end{array}$ & $18 \pm 6$ \\
\hline Visitas hospitalarias ( $M \pm D E)$ & $15 \pm 6$ \\
\hline Días del ingreso $(\mathrm{M} \pm \mathrm{DE})$ & $6 \pm 2$ \\
\hline Cirugía laparoscopia mano asistida (\%) & $62 \%$ \\
\hline
\end{tabular}

Dos receptores perdieron el trasplante y un donante falleció por causas ajenas a la donación. En relación al parentesco con el receptor el $41 \%$ fueron cónyuges, el $28 \%$ madres, el $24 \%$ hermanos y el $7 \%$ cuñados de los receptores como indica el Gráfico 1.

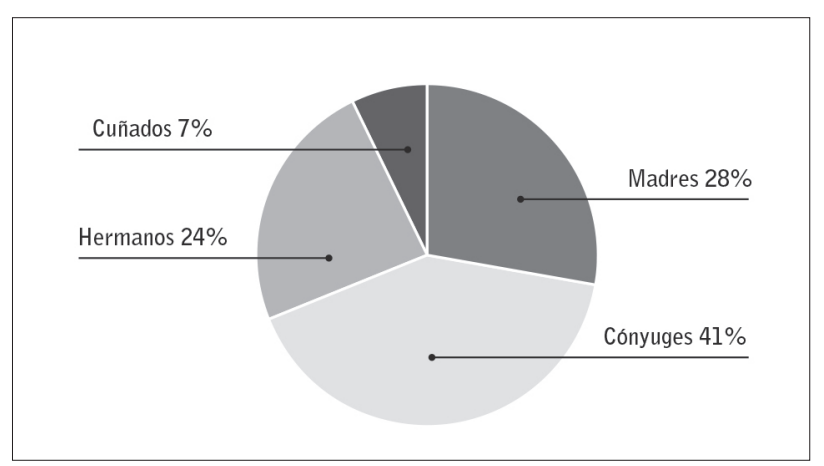

Gráfico 1. Parentesco de los donantes con el receptor.
La creatinina pre-trasplante fue $0,71 \pm 0,11 \mathrm{mg} / \mathrm{dL}$ y al alta $1,05 \pm 0,22 \mathrm{mg} / \mathrm{dL}$, no encontrándose diferencias estadísticamente significativas, y manteniéndose en estas últimas cifras durante todo el seguimiento como representa el Gráfico 2.

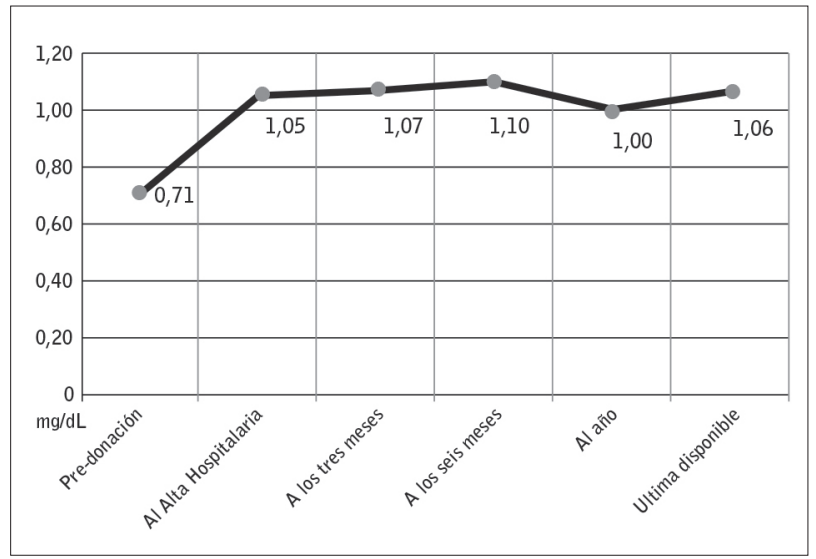

Gráfico 2. Evolución de creatinina sérica en el donante.

Más de la mitad (55\%) sufrieron algún efecto adverso durante los tres primeros meses post-donación, siendo dolores abdominales y molestias en la herida los más habituales y no encontrándose diferencias estadísticamente significativas entre donantes sometidos a cirugía laparoscópica, que los padecieron el 50\%, o a lumbotomía que los sufrieron el $64 \%$, si bien estos últimos tuvieron una estancia media de ingreso más prolongada $7 \pm 2$ días vs $5 \pm 1$ días $(p=0,015)$. Aquellos sometidos a cirugía abierta llevaban más meses trasplantados (46 \pm 39$)$ que los de cirugía laparoscópica $(28 \pm 14)$, sin alcanzar la significación estadística.

En relación a los resultados reportados por los donantes en la entrevista, de los 29 donantes, 24 contestaron el cuestionario de salud SF-36, y las puntuaciones medias en las dimensiones y en las puntuaciones sumarias se muestran en la Tabla 2.

Tabla 2. Puntuaciones en el SF-36 v2

\begin{tabular}{|lcc|}
\hline Dimensiones & $\mathbf{0 - 1 0 0}$ & $\mathbf{5 0 ( 1 0 )}$ \\
\hline Función física & $90,9 \pm 13,9$ & $52,6 \pm 5,8$ \\
\hline Rol físico & $82,9 \pm 23,1$ & $49,9 \pm 6,6$ \\
\hline Dolor corporal & $69,7 \pm 26,7$ & $46,7 \pm 9,6$ \\
\hline Salud general & $74,3 \pm 17,1$ & $52,7 \pm 7,6$ \\
\hline Vitalidad & $74,5 \pm 20,4$ & $53,5 \pm 9,2$ \\
\hline Función social & $86,9 \pm 16,6$ & $48,4 \pm 8,3$ \\
\hline Rol emocional & $85,9 \pm 20,8$ & $49,1 \pm 6,9$ \\
\hline Salud mental & $80,3 \pm 17,5$ & $53,5 \pm 8,7$ \\
\hline PCS & - & $50,6 \pm 6,27$ \\
\hline MCS & - & $50,7 \pm 8,98$ \\
\hline
\end{tabular}


* Las puntuaciones 0-100 van del peor al mejor estado de salud, respectivamente. En las puntuaciones 50 (10) la población de referencia tiene una puntuación media de 50, con una desviación estándar de 10, por lo que valores superiores o inferiores a 50 indican un mejor 0 peor estado de salud, respectivamente, que la población de referencia.

Sólo un donante tuvo una puntuación en la PCS con una desviación por debajo y 4 donantes ( $17 \%$ ) tuvieron una puntuación una desviación por debajo de la media en la MCS. Las respuestas a los ítems relacionados con el proceso de donación recogidos en el Checklist para las entrevistas con donantes de riñón de vivo propuesto por Casares se muestran en la Tabla 3.

\section{Discusión}

Nuestros resultados corroboraron lo aportado por los estudios previos ${ }^{2,7}$ y la CVRS de los donantes fue comparable a la población general tanto en los aspectos físicos como los mentales, explicable estos datos por la meticulosa selección que se lleva a cabo para ser donante, y es que los donantes son sometidos a rigurosos controles de salud para evitar posibles complicaciones tanto en el acto quirúrgico, recuperación inmediata como a medio y largo plazo. De hecho la media de consultas realizadas por los donantes es de dieciocho, siendo la mayoría antes del trasplante y necesitando quince desplazamientos al centro para hacerlas, lo que se traduce en que los donantes hacen en nuestro centro casi una sola consulta por

Tabla 3. Checklist para las entrevistas con donantes de riñón de vivo.

\begin{tabular}{|c|c|}
\hline ¿Cuándo y cómo oyó $\mathrm{Vd}$. hablar del trasplante renal donante vivo? & $24 \%$ receptor $76 \%$ nefrólogo \\
\hline ¿Quién le explicó los detalles de la cirugía del trasplante y cuántas veces? & $62 \%$ nefrólogo $24 \%$ urólogo $14 \%$ ambos \\
\hline $\begin{array}{l}\text { ¿En qué circunstancias se desarrolló la entrevista } \\
\text { (fue individual, o en presencia de terceros)? }\end{array}$ & $32 \%$ individual $37 \%$ con el receptor $31 \%$ con terceros \\
\hline ¿Entendió Vd. con claridad el procedimiento quirúrgico? & $100 \%$ si \\
\hline $\begin{array}{l}\text { ¿Entendió y conoció Vd. por completo los riesgos y beneficios del tratamiento } \\
\text { (incluyendo los riesgos a corto y a largo plazo para el donante } \\
\text { y la tasa de éxitos del implante del injerto en el receptor? }\end{array}$ & $100 \%$ si \\
\hline ¿Ha recibido información y explicaciones sobre tratamientos alternativos? & $100 \% \mathrm{si}$ \\
\hline $\begin{array}{l}\text { ¿Ha tenido suficiente tiempo para realizar preguntas? } \\
\text { ¿Se le ha invitado a realizar preguntas? }\end{array}$ & $100 \% \mathrm{si}$ \\
\hline ¿Ha consultado con alguien su decisión? & $60 \%$ con familia $40 \%$ no \\
\hline $\begin{array}{l}\text { ¿Ha recibido algún tipo de presión por algún miembro de la familia } \\
\text { o pariente cercano (por ejemplo, «si no estás de acuerdo con la donación, } \\
\text { el paciente morirá con seguridad»)? }\end{array}$ & $100 \%$ no \\
\hline ¿Fue su decisión completamente voluntaria? & $100 \%$ si \\
\hline ¿Tuvo ansiedad con respecto a la intervención quirúrgica? & $20 \%$ si $80 \%$ no \\
\hline ¿Tiene algún problema en su vida (por ejemplo, de trabajo o relaciones sociales)? & $100 \%$ no \\
\hline ¿Tiene algún problema financiero? & $100 \%$ no \\
\hline
\end{tabular}

Cabe resaltar que el $60 \%$ consultó el hecho con su familia, el $100 \%$ estaban bien informados de la donación y sus riesgos, y un $20 \%$ tuvo ansiedad respecto la intervención. A la cuestión planteada sobre si volverían a donar el $100 \%$ afirmó que volvería a hacerlo. Todos los pacientes tuvieron una puntuación de 100 en la Escala de Karnofsky. cada día que vienen, y en este sentido sería conveniente estudiar la posibilidad de centralizar las consultas en menos días de visita para disminuir estos trastornos a los donantes.

Al igual que un estudio reciente ${ }^{5}$ que encontraba que el $80 \%$ de los donantes estaba en la media o por encima en CVRS para su edad y género pero que el $9 \%$ de los donantes tenían un decremento de la PCS o MCS una desviación estándar por debajo de las normas poblacionales, en nuestro estudio encontramos un $17 \%$ con una MCS con una desviación por debajo, quizás explicable esta mayor frecuencia hallada por la gran prevalencia de 
donantes de género femenino que siempre parecen tener peores puntuaciones en los aspectos que evalúan la parte mental de la CVRS, tanto en otros cuestionarios de salud como en el SF-36 ${ }^{10}$. No se encontraron asociaciones estadísticas entre las medidas de CVRS y las variables estudiadas posiblemente por el tamaño muestral y por la variabilidad en el tiempo desde el trasplante de los casos.

La baja frecuencia de donantes varones merece una mención aparte, y es que parece que las mujeres temen menos someterse a una cirugía, a los efectos adversos y al dolor y en definitiva parecen ser más generosas con sus familiares. Quizás también por tener un mayor sentido práctico de la vida ya que mejorando la salud y calidad de vida de los familiares mejora la de toda la familia, disminuyendo las preocupaciones y el estrés y sobrecarga que provoca en una familia tener un miembro en diálisis ${ }^{13}$.

Sobre los resultados en la función renal, los donantes permanecen con una excelente función al alta del ingreso y esas cifras se mantienen estables durante todo el seguimiento como destacaron anteriormente otros autores $^{2,4}$. $Y$ en relación a los efectos adversos reportados, encontramos también similitudes con los hallazgos previos del estudio francés recientemente publicado donde los problemas en la herida y el dolor en la zona de la nefrectomía fueron los más frecuentes y donde el $98 \%$ volvería a donar pese a todo ${ }^{7}$, encontrándonos en nuestro centro con que la totalidad volvería a donar pese a que dos receptores ya han perdido el injerto. Sobre las técnicas quirúrgicas empleadas vemos, como en la misma línea que en estudios previos ${ }^{8,9}$ que la cirugía laparoscópica mano-asistida presenta ventajas claras al disminuir el número de días de hospitalización, y al disminuir el porcentaje de pacientes con efectos adversos, que aunque no alcanza la significación estadística, sí se observa una tendencia a sufrir menos acontecimientos los pacientes bajo cirugía laparoscópica.

Dado que el trasplante de donante de vivo es la primera elección recomendable para la mayoría de los pacientes con ERCA candidatos a trasplante, conocer las experiencias que han vivido los donantes y los efectos negativos es un tema de vital importancia para evitarlos en el futuro y mejorar la satisfacción de los donantes. Y en esta línea destacar la necesidad de dar información completa y detallada a los receptores sobre los resultados de los estudios llevados a cabo en los donantes para fomentar más el trasplante renal de vivo, ya que la mayoría de los receptores de injerto de cadáver son reacios a aceptar un órgano de un familiar teniendo un potencial donante de vivo como demostró un trabajo ${ }^{14}$ siendo la principal causa lo relacionado con la salud del donante (75\%) y el miedo a que se produzcan cambios en las relaciones entre receptor-donante. En esta línea también hay que resaltar la importancia que tiene para los donantes el entendimiento de su decisión por parte de toda la familia, y es que más de la mitad, el $60 \%$, consultó la decisión con sus familiares, y es que los posibles miedos del resto de la familia sobre los perjuicios que pueda sufrir el donante pueden ser una fuente de estrés extra para el donante al aumentarle los miedos, y esto puede generar más ansiedad de cara a la intervención, un 20\% manifestaron tenerla, o a largo plazo pensando en la posibilidad de que les falle el riñón que les queda. Habría que estudiar el apoyo familiar del donante con muestras más grandes analizando los diferentes grados de parentesco entre donante-receptor y si hay diferencias si la familia de sangre del donante es la misma que la del receptor, si hay hijos en común, etc. por la importancia que para los donantes tienen los resultados del trasplante en el receptor, y es que al hecho de que el bienestar de los receptores repercute directamente en su propio bienestar físico y mental y en el de toda la familia, se une la preocupación que pueden sentir dependiendo del vínculo algunos donantes como pueden ser las madres, debido a que disponen de una sola oportunidad de donar.

EL $100 \%$ de los entrevistados aseguró haber estado bien informado y entender con claridad el proceso por el que iba a pasar posteriormente, y es que una buena evaluación pre-donación y el asesoramiento inicial para que el donante pueda prever lo que le va a suceder durante el preoperatorio, ingreso y postoperatorio va a prepararle para los posibles acontecimientos adversos. Cabe destacar que el $76 \%$ oyó por primera vez hablar del trasplante de vivo al propio nefrólogo, lo que sugiere que estos donantes acompañan frecuentemente a los pacientes en sus visitas al nefrólogo. El 100\% aseguró que no tenía problemas financieros, ni de relaciones sociales ni que había recibido presiones familiares para donar, cosa lógica dado que no parece probable que se confiesen esas cosas aunque se produzcan, pero que son poco probables que ocurran ya que el equipo de trasplante está alerta cuando se dan casos poco claros o creíbles en relación al altruismo. Por otro lado se debe fomentar el seguimiento a los donantes con sobrepeso, con peores cifras tensionales, con problemas de salud mental y con una relación de menor grado con el receptor.

\section{Agradecimientos}

Los autores están agradecidos a los donantes de vivo de la consulta de trasplante renal del Hospital Universitario Central de Asturias por su participación amable y desinteresada. 
Recibido: 19 diciembre 2014

Revisado: 8 enero 2015

Modificado: 12 febrero 2015

Aceptado: 15 febrero 2015

\section{Bibliografía}

1. Matas AJ, Smith JM, Skeans MA, Thompson B, Gustafson SK, Schnitzler MA, et al. OPTN/SRTR 2012 Annual Data Report: kidney. Am J Transplant. 2014;14 Suppl 1:11-44.

2. Okamoto M. Long-term renal function, complications and life expectancy in living kidney donors. World J Transplant. 2012; 24(1):5-8.

3. Kroencke S, Fischer L, Nashan B, Herich L, Schulz $\mathrm{KH}$. A prospective study on living related kidney donors' quality of life in the first year: choosing appropriate reference data. Clin Transplant. 2012; 26(4):E418-427.

4. Fehrman-Ekholm I. View from a living donor. Clin Transpl. 2013:181-186.

5. Gross CR, Messersmith EE, Hong BA, Jowsey SG, Jacobs C, Gillespie BW, et al.; RELIVE Study Group. Health-related quality of life in kidney donors from the last five decades: results from the RELIVE study. Am J Transplant. 2013;13(11):2924-2934.

6. Watson JM, Behnke MK, Fabrizio MD, McCune TR. Recipient graft failure or death impact on living kidney donor quality of life based on the living organ donor network database. J Endourol. 2013; 27(12):1525-1529.

7. Briançon S, Germain L, Baudelot C, Bannay A, Virion JM, Thuong M. Quality of life of living kidney donor: a national report. Nephrol Ther. 2011 ;7 Suppl 1:S1-39.

8. Klop KW, Kok NF, Dols LF, Dor FJ, Tran KT, Terkivatan $\mathrm{T}$, et al. Can right-sided hand-assisted retroperitoneoscopic donor nephrectomy be advocated above standard laparoscopic donor nephrectomy: a randomized pilot study. Transpl Int. $2014 ; 27(2): 162-169$.

9. Dols LF, Kok NF, d'Ancona FC, Klop KW, Tran TC, Langenhuijsen $\mathrm{JF}$, et al. Randomized controlled trial comparing hand-assisted retroperitoneoscopic versus standard laparoscopic donor nephrectomy. Transplantation. 2014 ;97(2):161-167 Kidney Int. 1997; 52:10-20.

10. Vilagut G, Ferrer M, Rajmil L, Rebollo P, PermanyerMiralda G, Quintana JM, et al .El cuestionario de salud SF-36 español: una década de experiencia y nuevos desarrollos. Gac Sanit; 2005; 19: 135-50.

11. Casares M. Aspectos éticos de la donación renal de vivo. Nefrologia 2010;30(Suppl 2):14-22.

12. Schag CC, Heinrich RL, Ganz PA: "Karnofsky performance status revisited: reliability, validity, and guidelines"' J Clin Oncol. 1984; 2: 187-193.

13. Alvarez-Ude F, Valdés C, Estébanez C, Rebollo P; FAMIDIAL Study Group. Health-related quality of life of family caregivers of dialysis patients. $J$ Nephrol. $2004 ; 17(6): 841-50$.

14. de Groot IB, Schipper K, van Dijk S, van der Boog PJ, Stiggelbout AM, Baranski AG, et al. Decision making around living and deceased donor kidney transplantation: a qualitative study exploring the importance of expected relationship. BMC Nephrol. 2012; 7;13:103. 